\section{MARCHA A PIE URBANA Y REGIONAL Y MOVILIDAD EN LOS MODELOS DE CIUDAD PARA SANTIAGO DE CHILE}

María Isabel Pavez Reyes ${ }^{1}$

\section{Resumen}

Se hace una revisión general de las medidas en los planes de la etapa madura del Estado planificador urbano-regional chileno (1950-1979) y en el Urbanismo por el sector privado (1980-2010), que habrían favorecido, o perjudicado, la factibilidad de la marcha a pie en la ciudad de Santiago y en su entorno rural. El ejercicio de lectura se efectúa teniendo como referencia los conceptos en uso en cada época, modelo y proyecto, para reseñar, finalmente, el pensamiento actual para el logro de formas más ricas, diversas y sustentables de habitar el territorio.

\section{URBAN AND REGIONAL WALKING AND MOBILITY IN THE CITY MODELS FOR SANTIAGO DE CHILE}

María Isabel Pavez Reyes ${ }^{1}$ 
PALABRAS CLAVE: MARCHA A PIE, CIUDAD SUSTENTABLE, PLANIFICACIÓN DE SANTIAGO DE CHILE.

Fecha de recepción: 12.11.10

Fecha de aceptación: 21.03.11

1 Chile. Doctora en Arquitectura y Urbanismo de la Universidad Politécnica de Madrid. Académica del Departamento de Urbanismo, Facultad de Arquitectura y Urbanismo, Universidad de Chile.

Correo Electrónico: mpavez@uchilefau.cl

58 revista invi № 71 / Mayo 2011 / Volumen № 26: $57-85$
KEYWORDS: WALKING, SUSTAINABLE CITY, URBAN PLANNING OF SANTIAGO DE CHILE

Received: 12.11.10

Accepted: 21.03.11

1 Chile. Ph.D. in Architecture and Urban Planning, Universidad Politécnica de Madrid. Academic, Department of Urban Planning, Faculty of Architecture and Urban Planning, Universidad de Chile.

Email:mpavez@uchilefau.cl 


\section{Introducción}

La preocupación por la movilidad de los habitantes y las medidas tanto urbanísticas como arquitectónicas para facilitarla, han estado presentes desde épocas muy antiguas en las administraciones de las grandes aglomeraciones. En la Roma Imperial las necesidades de asistencia pública a 200.000 personas pobres registradas llevaron, en tiempos del principado de Claudio, a distribuir los alimentos de tal forma que los habitantes beneficiados no tuvieran que hacer largas caminatas ni aglomerarse esperando; así, fueron dispuestos 45 puntos de distribución en la ciudad, reglamentando, además, diversos días para ello y organizando a las personas en grupos, señalándose a cada uno una entrada con una oficina de despacho y un día determinado de distribución ${ }^{2}$. Por otra parte, la Lex Julia Municipalis del año 45 a. de C. disponía calles exclusivas para peatones -en el siglo XX, Copenhague las establece como novedad reciente, en 1954-, agregando a la innovación de las aceras heredadas de los etruscos, la existencia de cobertizos o alares voladizos en los tejados o en los balcones y en las fachadas de los inmuebles, proporcionando una apreciable protección contra la lluvia y el sol. Los foros y los pórticos también contribuyeron a otorgar acogida y confort a los

2 HOMO, León, pp. 163-164; 332-336. peatones. Adicionalmente, ya desde la dictadura de César, había quedado establecido un principio para los vehículos en cuanto al tránsito urbano: no podían circular los carros durante el día, desde la salida del sol hasta la hora décima, salvo algunas pocas excepciones ${ }^{3}$. Se priorizaba y protegía así al peatón.

El Urbanismo que se promueve actualmente para mejorar la calidad de vida de los habitantes en la perspectiva de la sustentabilidad del planeta, se interesa por el pasado, por el presente y por el futuro; no desestima los aportes precedentes, intenta ir dando respuesta día a día a los problemas aportando siempre algo más a lo que ya se tiene, y expresa en sus proposiciones una ética de solidaridad con las necesidades de los habitantes del futuro.

El ejercicio de lectura en este escrito sobre la factibilidad de la marcha a pie en la ciudad y la región de Santiago es pertinente toda vez que la marcha a pie representa una mayor sustentabilidad ambiental frente a otros modos de desplazamiento, además de ventajas económicas, sociales y de salud ${ }^{4}$.

En la planificación de Santiago de Chile en el siglo XX ya en 1936 había preocupación por la movilidad de los habitantes, tal como queda en evidencia

Ibídem.

4 Pozueta, 2009. 
en el proyecto intercomunal indicativo dispuesto por el Arqto. Luis Muñoz Maluschka, Jefe de la Sección de Urbanismo de la Dirección General de Obras Públicas. En este proyecto se trazó un relevante corredor de circunvalación comprendiendo tres anillos que permitirían desplazamientos sin tener que pasar por el centro, lo que bajaría la congestión en éste, y haría más segura y agradable la marcha a pie al interior del mismo ${ }^{5}$. Este corredor, que Muñoz logró construir sólo en un tramo de su anillo exterior en Las Condes hacia 1953, reaparecerá en la planificación intercomunal, ya oficial, desde 1960, combinado con otros trazados y medidas que incrementaron la factibilidad de la marcha a pie en la ciudad y en la región, como se verá más adelante.

La revisión general de las medidas en los planes de la etapa madura del Estado planificador urbanoregional chileno (1950-1979) ${ }^{6}$, y en el Urbanismo por el sector privado (1980-2010), que habrían favorecido, o perjudicado, la factibilidad de la marcha a pie en la ciudad de Santiago y en su entorno

5 Con anterioridad a esta proposición hay diversos proyectos que contemplaron un anillo circular o poligonal de circunvalación aunque de menor envergadura: Ansart, 1875; Carvajal, 1912; Coxhead, 1913; Pinto Durán, 1928, entre otros.

6 La autora considera una etapa previa, "instaurativa”, del Estado planificador urbano chileno, situada entre 1929 y 1949 . En la etapa "madura", desde 1950, se verá el reconocimiento legal de los niveles intercomunales de la planificación más allá de la comuna, la creación de la Dirección de Planeamiento, y comenzarán los estudios para los planes coordinados de 1958/60: PRIS 1960 y Plan Microregional de Santiago por el MOP (PAVEZ, 2006). rural, tiene como referencia los conceptos en uso en cada época, modelo y proyecto, reseñando, finalmente, el pensamiento actual para el logro de formas más ricas, diversas y sustentables de habitar el territorio ${ }^{7}$.

\section{La crítica de Mumford al protagonismo del automóvil y su influencia en los planificadores chilenos de los años 1950s}

La influencia de Lewis Mumford (1895-1990) en los arquitectos planificadores urbanos chilenos de los años 1950s, sumada a la crítica de ellos a varios de los postulados del Movimiento Moderno ${ }^{8}$, les hicieron expresar su rechazo al eventual advenimiento del modelo de ciudad dispersa ya en ocasión de su participación en el Seminario del Gran Santiago en 1957-589.

7 Este escrito refiere avances de investigación de la autora en su tesis doctoral (Pavez, 2006), y en FONDECYT 1090199 2009/2010, de su responsabilidad, citados en la Bibliografía.

8 PAVEZ, 2006.

9 UNIVERSIDAD DE CHILE, 1958. 
En los años 1950s Mumford criticó que en los Estados Unidos de América, el protagonismo del automóvil y la construcción de autopistas iban desarrollando un continuo de regiones urbanas de baja densidad, con asentamientos humanos dispersos, destruyendo la ciudad histórica y desfigurando el paisaje natural; ello iba teniendo como consecuencia la desintegración social y cívica que ya entonces imperaba en ciudades como Los Ángeles ${ }^{10}$. Estimó esta crítica que, de no cambiar esta situación mediante nuevas concepciones, todo se convertiría en un tejido indiferenciado y mediocre donde, para cumplirse las más elementales funciones, debería intervenir el automóvil privado al máximo, en tanto que el espacio rural estaría cada vez más distante $^{11}$. En su crítica al programa de carreteras aprobado en los Estados Unidos de América en 1957, denunció el círculo vicioso de la congestión, recordando que, a fin de subsanar el estancamiento de tránsito dentro y alrededor de las ciudades, los ingenieros viales iban extendiendo el daño que intentaban corregir al crear nuevas autopistas para servir a las ciudades. Se inducía, así, al abandono del transporte público para llegar a los centros urbanos y al uso del vehículo motorizado privado. Pero, las autopistas se mostraban congestionadas casi desde el primer día, ellas entorpecían las rutas tradicionales de circulación y limitaban el uso de las propiedades contiguas, en tanto que, en los

10 MUMFORD, Lewis (1958) ed. 1963.

11 CHOAY, Françoise, 1965. puntos donde arrojaban su flujo, creaban inevitables congestiones bajando la velocidad o, incluso, deteniendo el tráfico. Se creaban entonces otras autopistas similares y se proveía estacionamientos en el centro de las metrópolis, y la generosa respuesta expandía el ciclo de congestión sin promesa alguna de alivio hasta cuando todo el comercio y la industria, que originariamente la provocaron, se trasladara fuera de la ciudad huyendo de ella, quedando un desperdicio de autopistas y garajes ${ }^{12}$. Para tener un mínimo de comunicación y sociabilidad, la dueña de casa del asentamiento disperso se iba convirtiendo en una especie de chofer de taxi como ocupación diaria, y el costo para mantener en movimiento todo el sistema se traducía en policía inadecuada, hospitales con poco personal, áreas de recreo demasiado concurridas, bibliotecas y otros equipamientos mal sostenidos.

No soslayó el historiador de la civilización citado que el creciente uso del automóvil efectivamente proveía una base real de trabajo para una economía en expansión, sin embargo, eso no compensaba el propósito esencial de transporte, que es traer gente o mercancías a lugares donde se le necesita y concentrar la mayor variedad de bienes y de gente dentro de un área acotada para ampliar la posibilidad de elección sin que sea necesario trasladarse en automóvil a otro lugar. Un buen sistema

12 Ibídem. 
de transporte debe disminuir el transporte innecesario y, en cualquier caso, ofrecer diversidad de velocidades y de modalidades, a fin de ajustarse a los diferentes propósitos humanos ${ }^{13}$.

Mumford "probablemente el americano más lúcido", según apreciación del urbanista francés Gaston Bardet $^{14}$ - manifestó que, en la fascinación por el automóvil, todos habían olvidado cuanto más eficiente y flexible es el peatón. Por ello, según su parecer, todo plan de transporte urbano debería poner al peatón en el centro de todos sus proyectos, tratándole con respeto y con la misma importancia acordada al automóvil. Una caminata atractiva debía asociarse a un espacio público adecuado, con amplias aceras, mobiliario urbano practicable, arbolado y parterres de flores, todo asociado a cafés, librerías y otros al aire libre en zonas de usos mixtos compatibles con la residencia ${ }^{15}$. Concluyó entonces, al finalizar la década de los años 1950s, la necesidad de replanificar el interior de la ciudad para favorecer la circulación peatonal, y reconstruir y extender las formas de transporte público masivo, antes de disponer más autopistas urbanas.

13 Mumford promovió el uso de automóviles más pequeños y eléctricos para la ciudad

14 Bardet, 1952.

15 En los Estados Unidos de América, el ferrocarril y el metropolitano habían sido sistemáticamente sacrificados, favoreciendo los automóviles, teléfonos y aeroplanos, acarreando la declinación de las áreas centrales.
"No hay una solución de ingeniería puramente local para resolver el problema del transporte en nuestra época: no es posible hacer nada que sea una solución estable si no se tienen en cuenta todos los elementos necesarios de transporte: automóviles privados, ferrocarriles, aeroplanos y helicópteros, servicios de transporte en masa eléctricos y por ómnibus, hasta transbordadores $y$, finalmente, no el menor de todos, el peatón" $"$.

En cuanto a las áreas rurales y naturales próximas a las ciudades, estimaba Mumford que era necesario responder a la creciente afición de los habitantes urbanos a pasear a pie por ellas; para la recreación de fin de semana consideró que el conjunto del paisaje regional tenía que estar a disposición como "parque paisajístico" para los habitantes. Las rutas y los servicios recreativos deberían concebirse en la perspectiva de dispersar a la población de visitantes transitorios, y no de concentrarlos en un solo punto de atracción masiva. Una diversidad de oferta debería existir en todo el territorio, sin perturbar la actividad económica rural. Franjas de espacio público permitirían el efectivo acceso y práctica tranquila y segura de los habitantes a

16 MUMFORD, Lewis (1958) ed. 1963, p. 320. 
las orillas de los ríos, playas y lagos, a pie o en bicicleta $^{17}$.

Concluyó Mumford, en los años 1950s, que la política norteamericana de carreteras resultaba "anticuada".

\section{La opción por el modelo de ciudad semi-compacta en los planificadores chilenos, y factibilidad de la marcha a pie en sus proyectos para Santiago y su región desde 1960}

En la planificación de Santiago durante la etapa madura del Estado Planificador (1950-1979) -coordinando un proyecto de metrópoli con un proyecto de microregión ${ }^{18}-$, el modelo de ciudad considerado fue el semi-compacto, toda vez que observamos que la orientación del crecimiento dispuesta fue tanto al interior de la ciudad -por relleno de eriazos, por renovación y densificación, por

17 MUMFORD, Lewis (1958) ed. 1963

18 Concepto en la división regional de Chile por la Dirección de Planeamiento 1954, de acuerdo a los D. Leyes $N^{\circ} 150$ de 4 de julio de 1953, y N²24, de 22 de julio de 1953, establecida oficialmente por D.S. N²004 de 28 de octubre de 1954. Santiago quedaba en la "Región IV", incluyendo las Provincias de Aconcagua, Valparaíso y Santiago. Se dividió la Región IV en IV-A y IV-B, correspondiendo a esta última la cuenca del Maipo-Mapocho, con las Microregiones de San Antonio y de Santiago (PAVEZ, 2006). rehabilitación, y por crecimiento muy limitado en extensión de los bordes-, como en la microregión -por satelización en puntos precisos en su mayoría ya existentes en radios de 15, 30 y $45 \mathrm{~km}$ del centro de Santiago (desconcentración concentrada), con satélites que incrementarían su grado de autonomía relativa en función de la distancia a Santiago, para evitar desplazamientos innecesarios- ${ }^{19}$.

Con la desconcentración concentrada en núcleos urbanos menores, se evitaría disgregar los espacios agrarios y forestales en miles de fragmentos, pues cuando esto ocurre se vuelven cada vez más pequeños, menos funcionales y más desconectados los unos de los otros.

En este modelo de ciudad y proyectos coordinados de planificación, se implantó para la metrópoli los sub-centros metropolitanos de máxima autonomía (15 sub-centros), conectando éstos entre sí y con el centro histórico, dando una accesibilidad homogénea a toda la ciudad y cumpliendo una función integradora, además de evitar viajes en vehículo innecesarios. Un corredor de circunvalación com-

19 PARROCHIA et al., 1994/ 2001. 


\section{FIGURA 1. PLANO BASE DE SANTIAGO, BASE DEL PROYECTO INTERCOMUNAL DE SANTIAGO 1960- 1994}

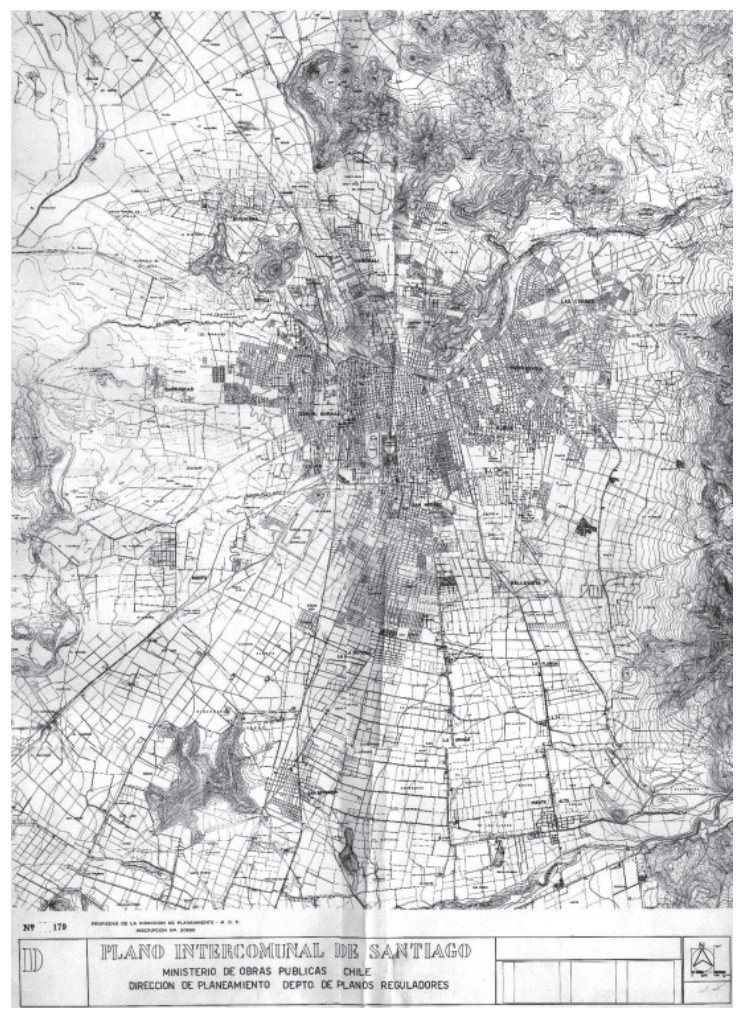

FUENTE: CHILE - M.O.P., Dir. Planeamiento, Depto. Planos Reguladores, "PLANO INTERCOMUNAL DE SANTIAGO", firmado po Director Ing. J. Kelemen; Jefe Depto. Arqto. O. Hufe; Jefe Plan Interc. Arqto. J. Honold; Urbanista Arqto. J. Parrochia (Colección de planos de 77 x 55 cm.; Escala Gráfica, escala original 1:20.000), impresión b/n, No2684, D-P, 1958, Instituto Geográfico Militar. [En: Colección "Juan Parrochia Beguin", Archivo Nacional de Chile, 2010]

\section{FIGURA 2. "PLANO INTERCOMUNAL DE SANTIAGO" $1958 / 60$}

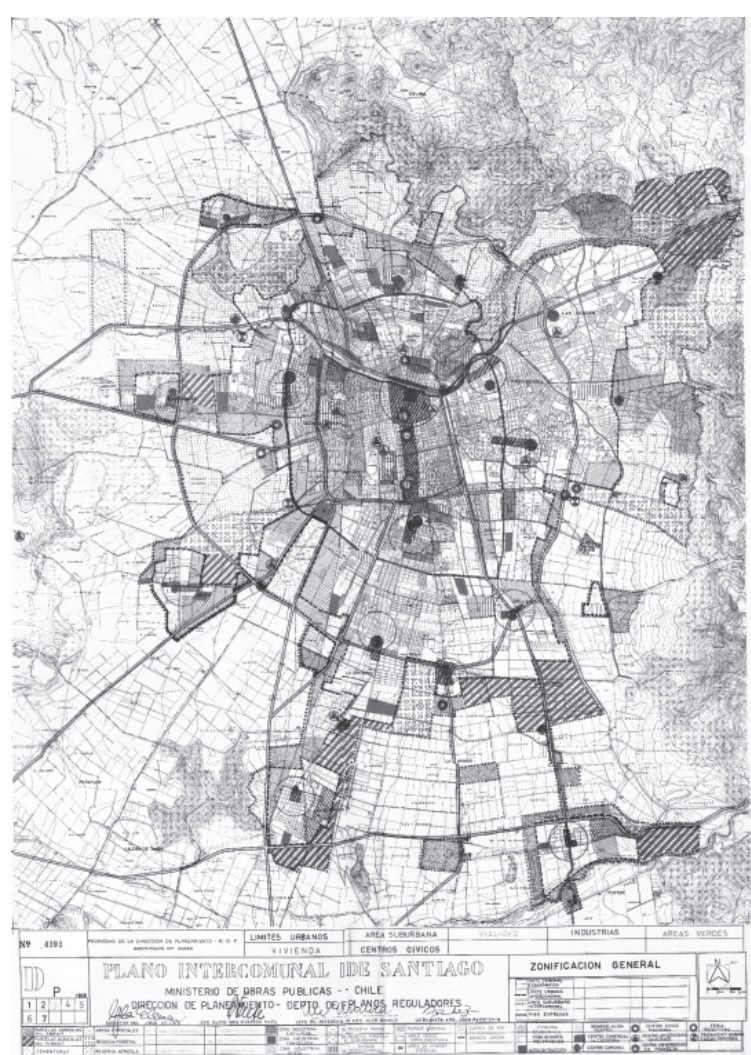

FUENTE: CHILE - MOP, Dir. Planeamiento, Depto. Planos Reguladores, firmado por Director Ing. J. Kelemen; Jefe Departamento Arqto. O. Hufe; Jefe Plan Intercomunal Arqto. J. Honold; Urbanista Arqto. J. Parrochia (Colección de planos de 77 x $55 \mathrm{~cm}$.: Escala Gráfica, escala original 1:20.000), impresión en colores sobre plano base blanco y negro, 1958, Instituto Geográfico Militar. [En: Colección "Juan Parrochia Beguin", Archivo Nacional de Chile, 2010]. 
FIGURA 3. PLANO MICRO-REGIONAL, REGIÓN IV-B , SANTIAGO DE CHILE, 1960.

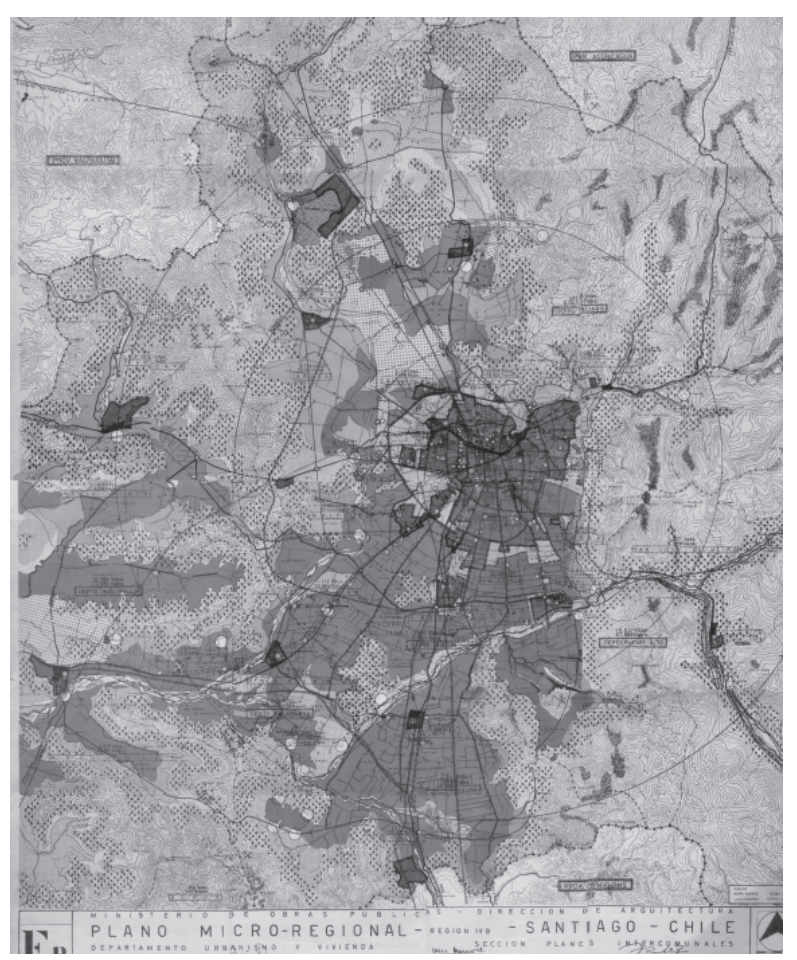

FUENTE: CHILE -M.O.P., Dir. Arquitectura, D. Urbanismo y Vivienda, S. Planes Intercomunales, Firmado por Director Arqto. E. Weil W.; Jefe Depto. Arqto. J. Honold D.; Jefe Plan Intercomunal Urbanista Arqto. J. Parrochia B. (F-P; 96 x 76 cm; inscripción N²5567), escala gráfica. Reducción de escala original 1:100.000; impreso en colores, Instituto Geográfico Militar, Santiago de Chile, s/f (1960). Pertenece a colección de planos. [En: Colección "Juan Parrochia Beguin", Archivo Nacional de Chile, 2010]. puesto de tres anillos de distribución, Américo Vespucio, Dorsal y un anillo intermedio, posibilitaría lo señalado, generando un cambio trascendente en la movilidad de los habitantes de Santiago al permitir los viajes de un lugar a otro de la ciudad sin tener que pasar por el centro principal, teniendo como consecuencia la descongestión del mismo y el ahorro de tiempo ${ }^{20}$.

A su vez, ello haría factible una mayor, mejor y más segura marcha a pie en el área central, lo que vendría a sumarse a las facilidades ofrecidas por las galerías cubiertas ya existentes al interior de varias manzanas.

En cuanto a las vías radiales fundamentales previstas para el acceso al centro, ellas definieron, en conjunto con los anillos del corredor de circunvalación, unos polígonos metropolitanos cuyo interior daría cabida a espacios verdes y de vialidad públicos de tamaño y dispersión media, además de los de escala vecinal, haciendo por ello factible también allí una más frecuente, mejor y más segura marcha a pie. Numerosas reservas para espacios verdes públicos fueron dispuestas en el marco de barrios más densos, de una mayor coordinación espacial, de una distribución más equilibrada de equipamientos y de una mayor animación lograda también a partir de la posibilidad de generar mixtura de usos compatibles con la residencia toda vez

20 Ibídem. 
que fuera posible ${ }^{21}$. Unos "bloques intercomunales" quedaron separados por "cuñas verdes", ligando la matriz geográfica con los parches verdes al interior de la ciudad, asunto relevante a la eficacia de la prestación de servicios ecológicos del conjunto.

En coordinación con la planificación metropolitana y regional habida desde 1960, el primer Plan de Transporte Metropolitano de Santiago (1969)22 dio especial importancia al transporte público en la ciudad y su región, adelantándose en algunos años a la crisis del petróleo de 1973, cuando por primera vez los transportes privados serán vistos como medios caros, no sólo a nivel individual sino también a nivel colectivo, y también a las políticas que en diversos países se trataron después de esta crisis, toda vez que el Plan de Transporte de Santiago de 1969 se coordinó con los proyectos de ordenamiento territorial para Santiago como un principio insoslayable.

Cabe destacar que las estrategias de desplazamiento del primer Plan de Transporte para Santiago no

21 En Chile, el concepto de las zonificaciones en polígonos monofuncionales aún se veía por muchos como un medio de ordenar la ciudad, por lo cual el tema de la mixtura de usos compatibles incluyendo la residencia, que ya promovía Muñoz Maluschka desde los años 1930, al parecer fue quedando relegado a un segundo plano. Sin embargo, se puede recordar que, por ejemplo, en el concurso internacional habido en torno a la Avda. NorteSur en 1972, la mixtura de usos compatibles con la residencia para las 16 manzanas del polígono de intervención fue parte de las bases.

22 LABBÉ A., Ernesto y MÁRQUEZ R., Jaime, 1974. restaban importancia al coche, pues la valoración de los transportes públicos permitiría que el coche pudiese existir en la ciudad.

El Plan de Transporte consideró, por una parte, una Red de Transporte Masivo Independiente (Red de Metro Urbano, complementada con una Red de Metro Sub-Urbano -expreso de suburbio- y una Red Vial Complementaria cubriendo la totalidad de la Metrópoli. Por otra, una Red de Transporte Superficial con sistema de buses tradicionales y eléctricos, con líneas de acercamiento a la Red de Transporte Independiente, para viajes mixtos en cuanto a los medios; líneas radiales para los enlaces directos interzonales, en los casos en que la Red de Transporte Independiente exigiera muchas transferencias, lo que aumentaría demasiado el tiempo de recorrido y líneas periféricas para los desplazamientos intrazonales y los enlaces interzonales periféricos de poco tráfico ${ }^{23}$.

Otros sistemas futuros para zonas céntricas y áreas especiales (aeropuertos, campos de ski, etc.) tam-

23 Ibídem 
bién estaban previstos, así como una Red de Transporte de Trenes Sub-Urbanos que favorecería el acceso por transporte público masivo a los satélites y áreas rurales de interés a la recreación de los habitantes de la metrópolis, y una nueva regulación del tránsito, del transporte y de su control.

En cuanto a los asentamientos y posibilidades de recreación en las áreas rurales, la planificación por el Estado de Chile imaginó un conjunto de aldeas balnearios en el entorno de Santiago, comprendiendo unidades de 1.000 a 5.000 habitantes -y más en la temporada alta- en el marco de una naturaleza limpia de contaminación, captando paisajes de interés y microclimas sanos. En ellos se ubicarían también refugios, hospederías de estudiantes y otros tipos de residencias para turistas, veraneantes y excursionistas. Se establecerían en terrenos no agrícolas, pudiendo instalarse en ellos, conjuntos de alto interés urbanístico y arquitectónico ${ }^{24}$

Destacó la conciencia de los planificadores de Estado sobre el valor del río Mapocho no sólo como elemento de identidad ligado a la fundación de la ciudad, sino también como espacio verde necesario a la salud y necesidades de recreación masiva, y lugar desde donde se focalizaba un macropaisaje regional espectacular, por lo cual fue considerado desde entonces como el "Parque Intercomunal Cuenca del Mapocho" en toda su extensión. Jun-

24 Un detalle de los puntos puede encontrarse en Parrochia et al., $1994 / 2001$. to a él habría satélites balnearios entre Carén y El Monte. Al respecto, no es casual que la primera autopista regional construida en Chile, la Ruta 78, uniendo Santiago al Puerto de San Antonio -comenzada en 1966 por el Ministerio de Obras Públicas-, no se dispuso a orillas de dicho corredor fluvial, sino a distancias entre 1,5 y $4 \mathrm{~km}$ aproximadamente, evitando con ello perturbar la tranquilidad del entorno inmediato al río, además de respetar la banda lateral de protección/infiltración. De esa forma, y teniéndose ya una serie de caminos paralelos y perpendiculares asociados a la actividad agrícola, sería posible acercarse al río en un ambiente tranquilo y con velocidades moderadas, haciendo factible una marcha a pie y en bicicleta más segura en ese ámbito.

Debe mencionarse, también, la reserva oriental no urbanizable de la ciudad, una banda de $5 \mathrm{~km}$ de ancho a lo largo de todo el pie de monte andino metropolitano (28 km, entre el Mapocho y el Maipo), con las funciones de servir de área de infiltración de aguas con varias finalidades: para la protección de la ciudad de las "avenidas" y para la recarga de la napa bajo ella; también de corredor biológico y ecológico, donde, sin impedir labores agropecuarias, estaba prevista la posibilidad de senderos peatonales turísticos y recreacionales, disfrutando de su condición de "balcón" de la ciudad"25.

25 El gobierno del General Pinochet ignoró estas funciones e incluso, el valor estratégico del agua subterránea en caso de sequía 


\section{La opción por el modelo disperso para Santiago desde 1979}

\section{EL ADVENIMIENTO DE LA POLÍTICA NEOLIBERAL RADICAL}

Cuando, desde principios de la década de 1980, en Europa empezó a promoverse el incremento, restauración, mejoramiento, diversificación y sustentabilidad de los espacios públicos, en Chile comenzó a aplicarse la política neoliberal en forma radical, generándose un proceso de desplanificación urbana, perdiéndose parte de las previsiones de los planes de 1960, entre ellas las que iban favoreciendo la posibilidad de practicar la marcha a pie en condiciones de seguridad y confort, y promoviéndose paulatinamente el incremento del uso del automóvil al permitir desarrollos inmobiliarios en polígonos monofuncionales fuera del continuo urbanizado, los que necesariamente debían valerse

-o de sequía simultánea con otros eventuales sucesos adversos-, toda vez que dio comienzo a la urbanización paulatina de esta banda, la que terminará por impermeabilizar el suelo, generando, además, recurrentes y altos volúmenes de agua de escorrentía formados en cortos períodos, con el consiguiente daño a la propiedad pública y privada. En 1974, también se autorizó allí una central nuclear que hoy se ve rodeada de poblaciones a menor distancia de lo deseable, además de estar todos sobre la falla de Ramón. En el caso de un terremoto, el primer efecto en un área de piedemonte es el deslizamiento de terrenos. de autopistas para su conexión con el centro, y de centros comerciales concentrados para abastecerse.

Con la Política de Desarrollo Urbano establecida desde 1979, fue el Diseño Urbano el que se puso al servicio de las nuevas formas privadas de producir ciudad, las que se anunciaron luego del retroceso del Estado chileno y su reacomodo para su funcionalidad al nuevo modelo de desarrollo económico y social ${ }^{26}$. El Diseño Urbano ya se había practicado en Chile en el dominio público por la Corporación de Mejoramiento Urbano, CORMU, en los años sesenta, e incluso antes -en los momentos que en el contexto internacional el Movimiento Moderno declinaba-, teniendo al proyecto arquitectónico de corto y mediano plazo como el, relativamente nuevo, instrumento de transformación paulatina de la ciudad ${ }^{27}$.

Destacan Raposo et al. ${ }^{28}$ que, a diferencia de la actual práctica privada del Diseño Urbano (megaproyectos residenciales en el medio rural, en esquema de condominios privados, un archipiélago de ínsulas sub-urbanas), el Diseño Urbano de la

26 RAPOSO, et al., 2005

27 Ibídem.

28 Ibídem. 


\section{TABLA 1. CIUDADES SATÉLITES EXISTENTES Y PROYECTADAS EN LA MICRO-REGIÓN DE SANTIAGO 1960-1994}

\begin{tabular}{|c|c|c|}
\hline Tipo de satélites y población & $\begin{array}{l}\text { Ubicación } \\
\text { kms. desde el centro de } \\
\text { la metrópolis }\end{array}$ & Nombres \\
\hline $\begin{array}{l}\text { SATÉLITES RESIDENCIALES: } \\
\text { Desde aldeas ( } 5.000 \text { habitantes aprox.), hasta } \\
\text { conjuntos de barrios, conformando ciudades } \\
\text { (hasta } 100.000 \text { habitantes). }\end{array}$ & $\begin{array}{l}\text { Ubicados a una distancia } \\
\text { promedio de } 10 \text { a } 15 \mathrm{kms} \text {. }\end{array}$ & $\begin{array}{l}\text { SAN BERNARDO, MAIPÚ, LA AFRICANA, PUDAHUEL, QUI- } \\
\text { LICURA, SAN FRANCISCO DE LAS CONDES, EL ARRAYÁN, } \\
\text { PEÑALOLÉN, PUENTE ALTO, el poblado de PUDAHUEL, LA } \\
\text { PINCOYA, MACUL ALTO. }\end{array}$ \\
\hline $\begin{array}{l}\text { SATÉLITES AGRÍCOLAS: } \\
\text { Industria relacionada con una producción } \\
\text { agrícola intensiva (productos típicos del área), } \\
\text { autónomas hasta el nivel de pequeña ciudad } \\
\text { (comercio, educación, salud, administra- } \\
\text { ción, etc.), entre } 30.000 \text { y } 50.000 \text { habitantes. }\end{array}$ & $\begin{array}{l}\text { Ubicados a una distancia } \\
\text { promedio de } 30 \mathrm{kms} \text {. }\end{array}$ & $\begin{array}{l}\text { BUIN, TALAGANTE, LO PRADO, LAMPA, COLINA, SAN JOSÉ } \\
\text { DE MAIPO, sin perjuicio de mantener sub-centros de esta } \\
\text { misma especie en: MALLOCO, PADRE HURTADO, PEÑAFLOR, } \\
\text { BATUCO, ESTACIÓN COLINA, EL PRINCIPAL DE PIROUE, } \\
\text { ISLA DE MAIPO, etc. }\end{array}$ \\
\hline $\begin{array}{l}\text { SATÉLITES INDUSTRIALES: } \\
\text { Nueva industria pesada, y la trasladada desde } \\
\text { Santiago. Entre } 100.000 \text { y } 200.000 \text { habitantes } \\
\text { con equipamiento para ciudad intermedia. }\end{array}$ & $\begin{array}{l}\text { Ubicados a una distancia } \\
\text { promedio de } 45 \mathrm{kms} \text {. } \\
\text { En terrenos de mala calidad } \\
\text { agrícola; en los corredores } \\
\text { de desarrollo de la metró- } \\
\text { poli de Santiago. }\end{array}$ & $\begin{array}{l}\text { LO ÁGUILA SUR, en el corredor de transporte longitudinal ca- } \\
\text { minero y ferroviario sur; MELIPILLA, en el corredor caminero } \\
\text { y ferroviario poniente, hacia San Antonio; CURACAVÍ, en el } \\
\text { corredor Santiago - Valparaíso, pasando por un nuevo túnel } \\
\text { (Lo Prado, } 3 \mathrm{~km} \text { de largo, inaugurado en 1970); CHICAUMA, } \\
\text { en la bifurcación del corredor caminero y ferroviario hacia el } \\
\text { norte y el nuevo corredor caminero y ferroviario hacia Viña del } \\
\text { Mar y Valparaíso, por La Dormida. }\end{array}$ \\
\hline $\begin{array}{l}\text { SATÉLITES BALNEARIOS: } \\
\text { Aldeas de } 1.000 \text { a } 5.000 \text { habitantes, y más en la } \\
\text { temporada alta. } \\
\text { En el marco de una naturaleza limpia de conta- } \\
\text { minación, captando paisajes de interés y micro- } \\
\text { climas sanos. } \\
\text { En ellos se ubicarían también refugios, hospe- } \\
\text { derías de estudiantes, y otros tipos de residen- } \\
\text { cias para turistas, veraneantes y excursionis- } \\
\text { tas. }\end{array}$ & $\begin{array}{l}\text { Ubicados en terrenos no } \\
\text { agrícolas, pudiendo insta- } \\
\text { larse en ellos, conjuntos de } \\
\text { alto interés urbanístico y } \\
\text { arquitectónico. }\end{array}$ & $\begin{array}{l}\text { La Dehesa; el fondo del Valle del Arrayán; el fondo de los ríos } \\
\text { Mapocho, San Francisco y Molina; la alta cordillera andina y } \\
\text { áreas de ski; a lo largo del río Maipo, desde San Juan de Pirque } \\
\text { y La Obra hasta el fondo del río Colorado; el río Yeso, el Volcán } \\
\text { y Las Melosas, incluyendo los balnearios de ski de cordillera } \\
\text { de Lo Valdés y Lagunillas; en los contornos de la laguna de } \\
\text { Aculeo y del río Maipo medio, entre los cerros de Lonquén y } \\
\text { Melipilla; en el río Mapocho, entre Carén y El Monte; en el valle } \\
\text { del Puangue, entre Curacaví y María Pinto; en Chicauma; en el } \\
\text { valle del estero Colina. (Un total de } 39 \text { puntos de interés indi- } \\
\text { cados en el plano micro-regional). }\end{array}$ \\
\hline
\end{tabular}

FUENTES: PARROCHIA BEGUIN, J. (autor y co-autor cont.), PAVEZ REYES, M. I. (comp.), 1994; / CHILE - M.O.P., Dir. Arquitectura, Depto Urbanismo y Vivienda, S. Planes Intercomunales, "PLANO MICROREGIONAL - REGIÓN IV-B SANTIAGO DE CHILE". Fdo. Director Arqto. E. Weil W.; Jefe Depto. Arqto. J. Honold D.; Jefe Plan Intercomunal Urbanista Arqto. J. Parrochia B. (F-P; 96 x 76 cm; inscripción N²5567), escala gráfica. Reducción de escala original 1:100.000; impreso en colores, Instituto Geográfico Militar, Santiago de Chile, s/f (1960). Pertenece a colección de planos. [En Colección "Juan Parrochia Beguin", Archivo Nacional de Chile, 2011]. 
FOTO 1. EL RÍO MAPOCHO ACTUALMENTE, A LA ALTURA DE TALAGANTE

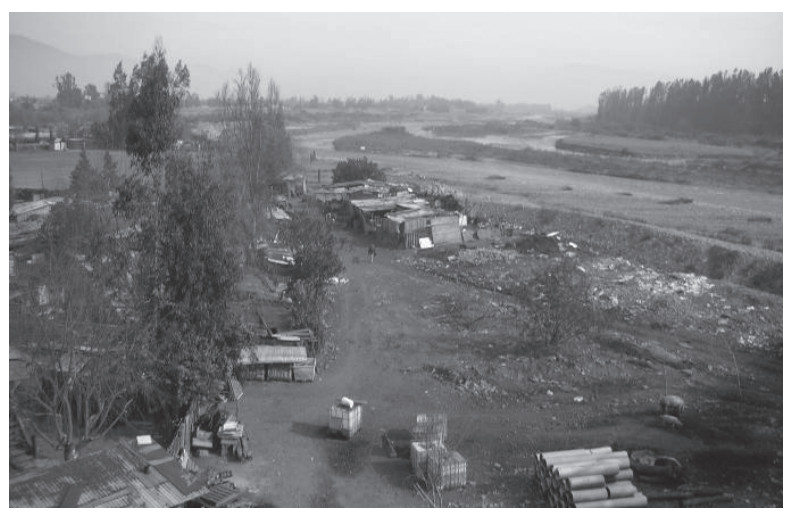

FUENTE: Henríquez O., P. 2010

\section{FOTO 3. VISTA DEL FRENTE ANDINO DE SANTIAGO}

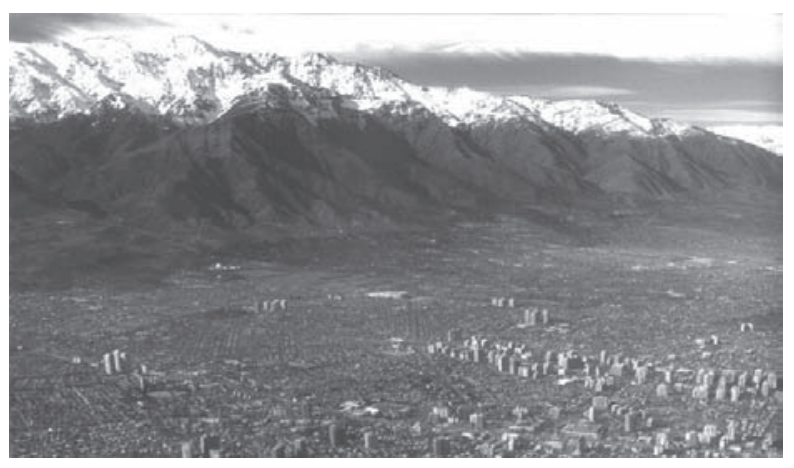

FUENTE: Sección de foto, original color, de G. Wenborne, en: Santiago, Ed. Kactus s/f., p. 50, circa 2000, reproducción con fines culturales.

70 revista invi № 71 / Mayo 2011 / Volumen № 26: 57-85
FOTO 2. EL RÍO MAPOCHO ACTUALMENTE, A LA ALTURA DE PADRE HURTADO

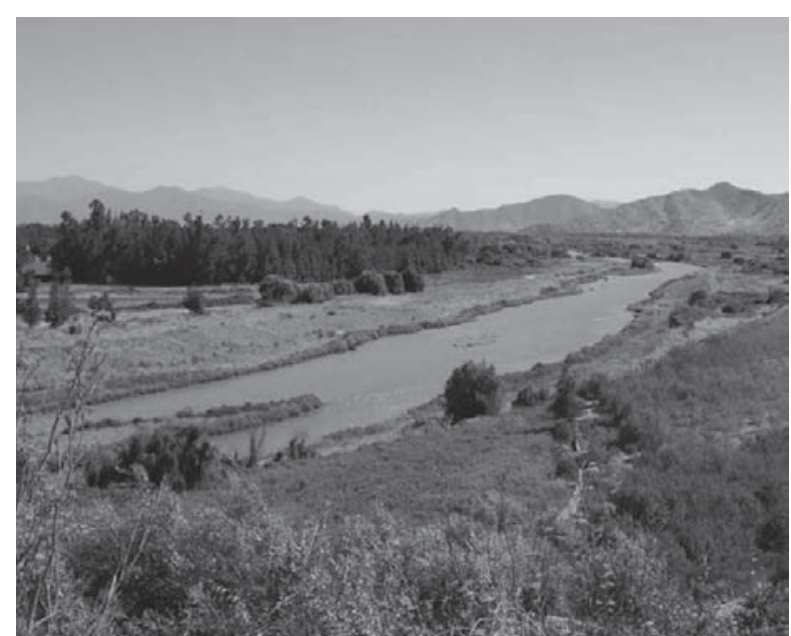

FUENTE: Henríquez O., P. 2010. 
FIGURA 4. REMODELACION SAN BORJA, EN SANTIAGO. CORMU

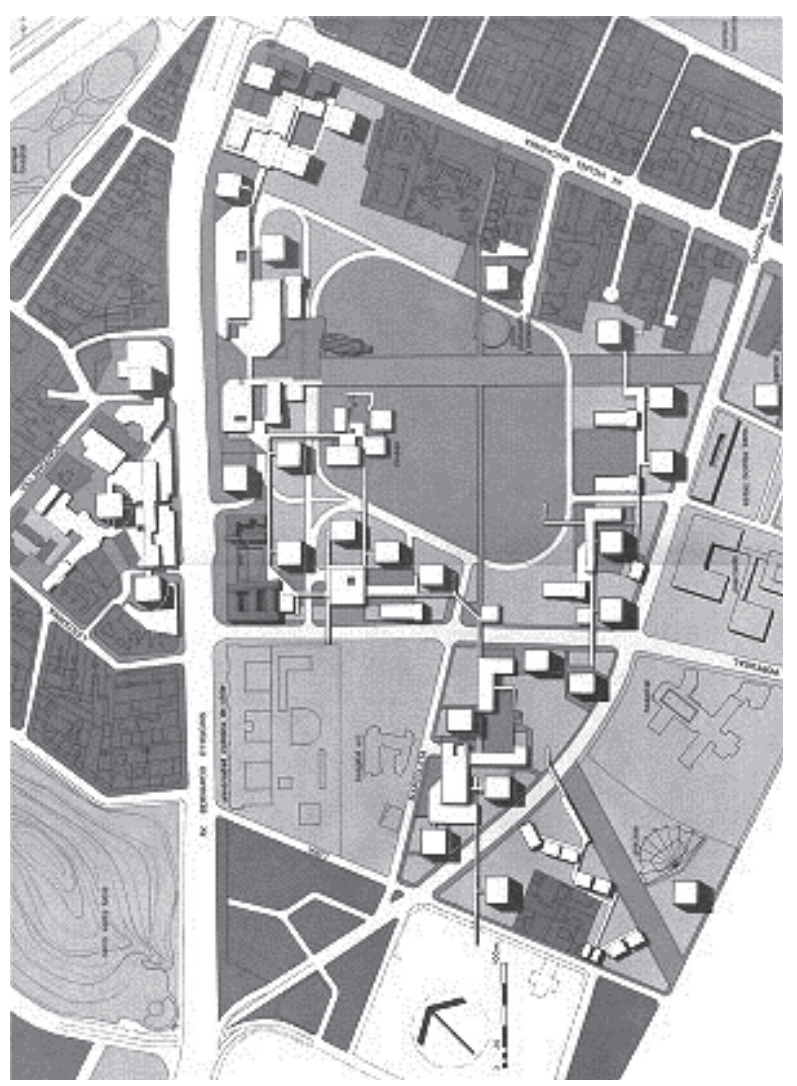

FUENTE: CA Nº46, Santiago, diciembre 1986, pp. 31-32.
FIGURA 5. CONCURSO INTERNACIONAL "AREA DE REMODELACIÓN EN EL CENTRO DE SANTIAGO DE CHILE". $1{ }^{\text {ER PREMIO (ARGENTINA) }}$

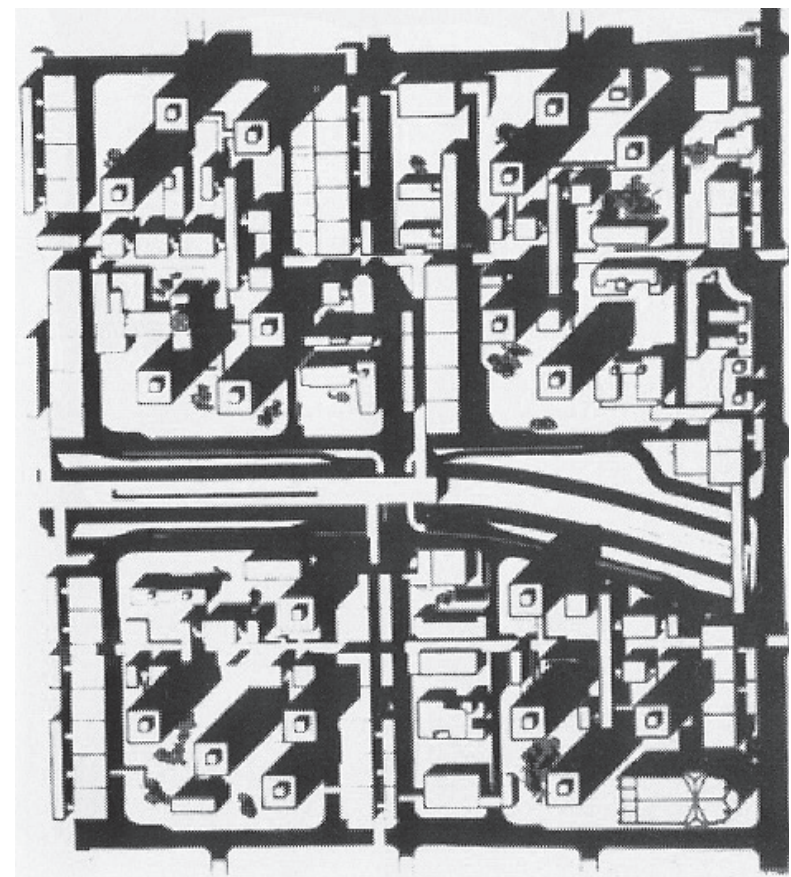

FUENTE: AUCA N²4-25, 1973 (Edición proyectada antes del 11 de septiembre de 1973), pp. 23-34. 
CORMU intentó recuperar los valores de la centralidad y de las áreas pericentrales, instaurar una dialéctica entre la imagen de lo viejo y de lo nuevo (lo que vale también para la transformación de la sociedad), y articular y entretejer lo social de los dominios y escalas públicos, semipúblicos y privados. También que, en el último cuarto del siglo XX, la disciplina urbanística y el Diseño Urbano en Chile se extraviaron ${ }^{29}$. La práctica del Diseño Urbano metropolitano se puso al servicio de la especulación inmobiliaria en el ámbito "suburbano"; en la ciudad tradicional permaneció disponible la posibilidad del micro-diseño urbano edilicio ${ }^{30}$.

...lo que destituye con mayor efectividad la posibilidad disciplinaria del urbanismo en el contexto nacional es el pensamiento neoliberal sobre lo urbano. Conforme a éste, es el mercado operando bajo condiciones de libre competencia, el que mejor imprime un orden funcional y expresivo de la ciudad. La ciudad es un lugar de mercado (market place). Desde esta óptica, los instrumentos de planificación urbana deben ser tan sólo reglas del juego acordadas, recursos complementarios que apoyan la gestión inmobiliaria de los desarrolladores urbanos con los cuales ha de plasmarse efectivamente la ciudad y sus transformaciones. El gran motor de este proceso es la maquinaria de la propiedad y su accionar en el negocio inmobiliario, el contextoliberado de todaintervención política ${ }^{31}$.

29 Ibídem

30 Ibídem.

31 Ibídem, p. 151

72 revista invi № 71 / Mayo 2011 / Volumen N ํo 26: 57-85
La ultra liberal política de desarrollo urbano, legal desde 1979, afirmó que el suelo urbano no era un recurso escaso y que su aparente escasez -también los principales problemas de las ciudades- era causada por la excesiva intervención del Estado en los mercados de suelos (MINVU, 1979).

La eliminación de las normas sobre "límites urbanos" dio paso a extensas áreas de "expansión urbana"32, desestimando las medidas anteriores de protección de las áreas agrícolas de riego en el entorno de Santiago, y de las diversas áreas no urbanizables previstas desde 1960 -como aquélla del pie de monte andino antes citada-.

El decreto 3.516 de 1980, permitió, además, la subdivisión del suelo agrícola hasta una superficie de media hectárea, dando origen a las "parcelas de agrado", lo cual contribuyó al desarrollo de la forma dispersa de crecimiento y a fragmentar el área rural.

La política de 1979 fue moderada en 1985, pero el proceso de especulación y subdivisión de tierras continuó. En 1994 surgió un nuevo plan para la ciudad, el Plan Metropolitano de Santiago, el cual dentro de su ámbito de actuación incorpora 37 comunas, incluyendo la Provincia de Santiago, más los municipios de San Bernardo, Puente Alto, San José de Maipo, Pirque y Calera de Tango.

32 Decreto 420, 1979, MINVU, crea el Área de Expansión Urbana. para Santiago de Chile / María Isabel Pavez Reyes 
FIGURA 6. "ESTUDIO DE ÁREA DE EXPANSIÓN DE SANTIAGO", MINVU 1979, QUE INCLUYE EL ÁREA DISPUESTA COMO INEDIFICABLE EN EL PIEMONT ANDINO, POR EL PLAN REGULADOR INTERCOMUNAL DESDE 1960.

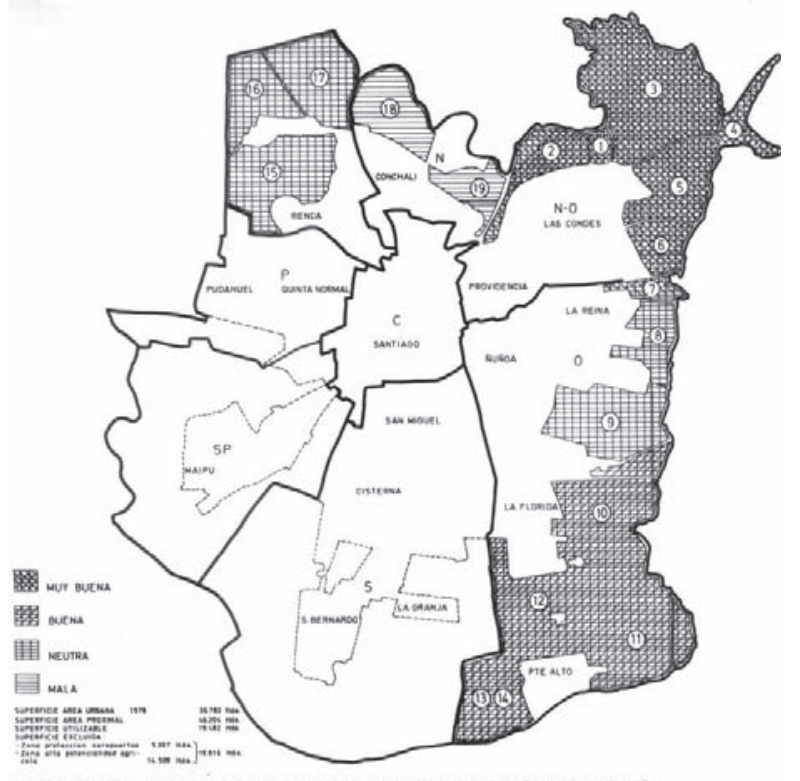

ESTUDIO DE AREA DE EXPANSION DE SANTIAGO (MINVU 1979)

FUENTE: MINVU, División de Desarrollo Urbano, 1979. "Política Nacional de Desarrollo Urbano. MINVU 1979". En: Revista AUCA No37, Santiago de Chile, pp. 33-37.
FIGURA 7. PLAN REGULADOR METROPOLITANO DE SANTIAGO, 1994.

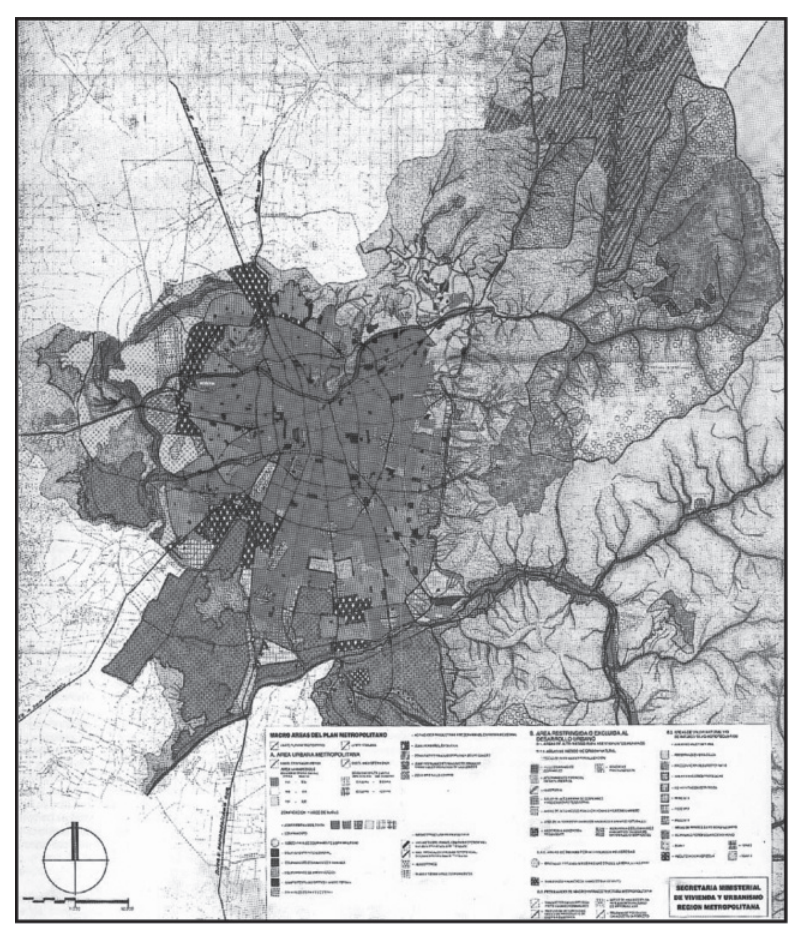

FUENTE: MINVU. 


\section{FIGURA 8. VERSIÓN ACTUALIZADA DEL PRMS QUE INCLUYE LAS MODIFICACIONES OUE INCORPORAN LA PROVINCIA DE CHACABUCO (1997) Y LAS PROVINCIAS DE MELIPILLA Y TALAGANTE (2006).}

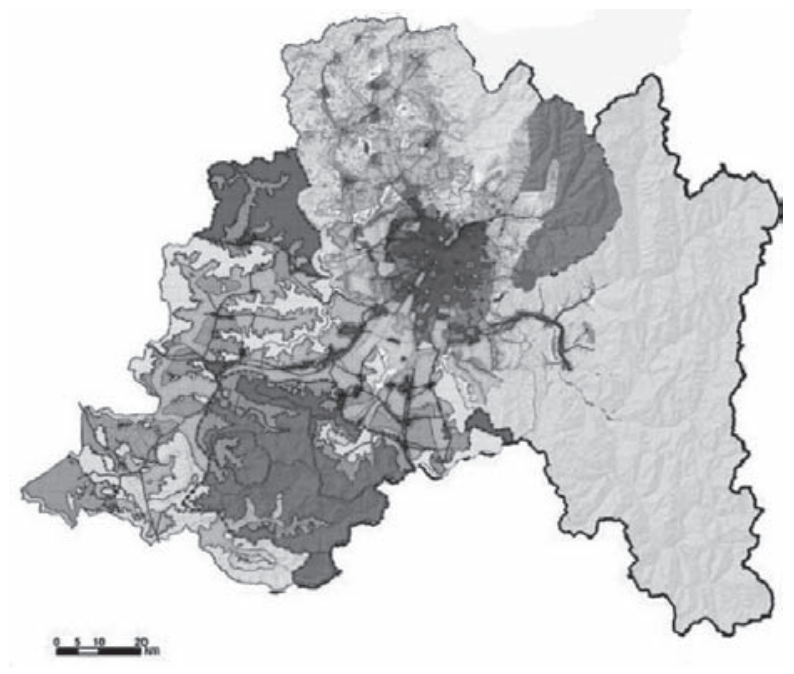

FUENTE: MINVU.

Este Plan promueve el crecimiento en densificación, y las regulaciones aumentan en el área excluida al desarrollo urbano, definiendo usos especiales de protección ecológica, de interés silvoagropecuario y de riesgo por factores naturales (inundaciones, remoción en masa, etc.).

74 revista invi № 71 / Mayo 2011 / Volumen N ํㅜ 26: 57-85
En 1997, se incorporó al PMS el concepto de "condicionamiento urbano", instaurando zonas urbanizables con desarrollo condicionado al diseño de planes maestros y la provisión privada de equipamientos e infraestructura. Los crecimientos pronto se empezaron a producir sobre áreas de interés silvoagropecuario. En el año 2000 la política nacional de desarrollo urbano se derogó y no ha sido reemplazada por otra. Desde 2003 es lícita la instalación de conjuntos habitacionales en el área rural -ajenos a una actividad económica agrícola o industrial-, cualquiera que sea el tamaño de dichos conjuntos, y al margen de toda planificación urbana-regional.

\section{LAS AUTOPISTAS URBANAS APOYANDO EL DESARROLLO DE LA CIUDAD DISPERSA.}

Transcurridos 16 años del cambio del modelo de desarrollo económico y social, la Secretaría de Planificación de Transporte presentó un Plan de Desarrollo del Sistema de Transporte Urbano Gran Santiago 1995-2010, basado en las disposiciones del Plan Regulador Metropolitano de Santiago (1994), ${ }^{33}$ teniendo entre algunos de sus objetivos: incorporar los costos de inversión y operación del sistema de transporte a las decisiones de localización de hogares y actividades; proveer las condiciones para aumentar considerablemente los viajes a pie o en medios no motorizados de transporte,

33 REPÚBLICA DE CHILE, 1995. 
basándose en el impulso a 11 sub-centros urbanos del plan de ordenamiento; realizar inversiones en educación para retener parte de los viajes dentro de un ámbito espacial más reducido, y priorizar la localización de actividades generadoras de empleo en dicho ámbito ${ }^{34}$; fortalecer, o crear, organismos para coordinar la acción del Estado y las intervenciones privadas sobre la ciudad (Alcaldía Mayor) ${ }^{35}$. Una nueva política de concesiones viales urbanas -funcional al modelo de ciudad dispersa- venía gestándose desde 1992.

La construcción de autopistas promovió el uso del automóvil privado; la lógica señalaba que habían aumentado los ingresos, por lo que había más autos y, por tanto, se necesitaban más vías. Éstas librarían de la congestión y servirían para descontaminar, pues -se decía- a mayores velocidades, los autos contaminan menos ${ }^{36}$. La medida comprendió inicialmente 7 autopistas.

Desde 1991 hasta 1998, el arquitecto Marcial Echenique $^{37}$ asesoró al MOP para efectos de diseñar el siste-

34 La decisión del Presidente de la República de hacer llegar una línea de Metro hasta Puente Alto, fue contradictoria con estas medidas, y tuvo más relación con los resultados del censo de 1992, que registró medio millón de personas en Puente Alto, vistos como futuros electores.

35 REPÚBLICA DE CHILE, 1995.

36 QUIJADA, 2003

37 Arqto. chileno, titulado en la P. Universidad Católica, Premio Nacional de Urbanismo de Gran Bretaña en 2000, catedrático en la Universidad de Cambridge.

\section{FIGURA 9. PROGRAMA DE CONCESIONES VIALES URBANAS Y PUNTOS DE CONTROL DE FLUJOS EN SANTIAGO, INCLUYENDO LA VÍA "ORBITAL".}

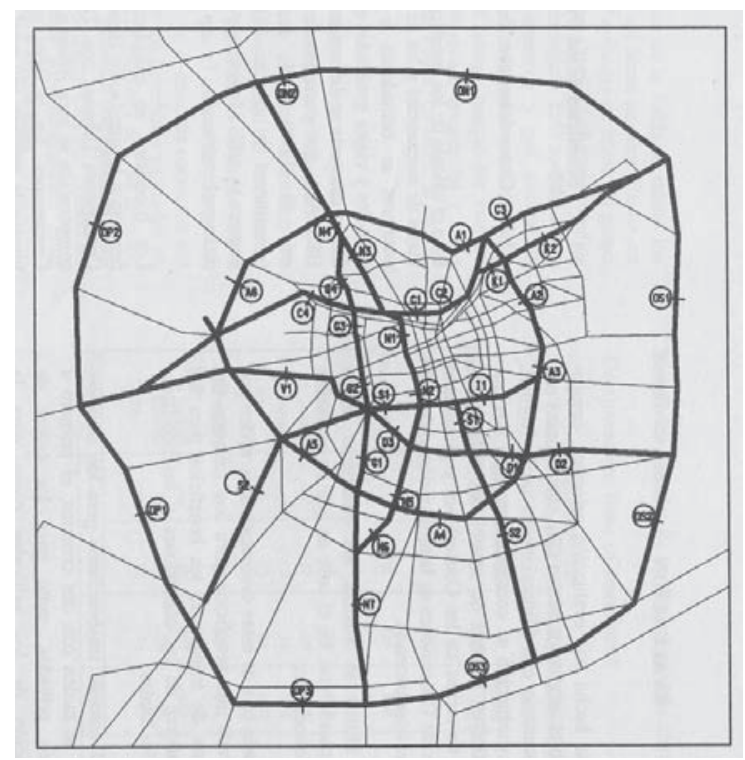

FUENTE: CHILE, MOP, Dirección de Planeamiento - ME\&PMECSA-INECON. Dic. 1995. Análisis Programa estratégico de inversiones. Macro Zona Central. Sintesis ejecutiva. 43 p. ilustradas. 
ma de autopistas urbanas ${ }^{38}$. En su opinión, el acceso al automóvil es "la gran conquista social"39. Respecto del papel que cumple el transporte público en "la ciudad eficiente", señaló desde Inglaterra en $2004^{40}$ :

Es muy importante, pero tiene que ser limitado al acceso hacia el centro de las ciudades; hacia la zona céntrica es muy difícil transformar las calles porque se empieza a destruir el patrimonio histórico. Y también para los nuevos centros que van surgiendo, como la avenida El Bosque [adscrito al subcentro lineal oriental de Santiago de Chile], que es de grandes oficinas, porque esas calles están muy copadas. Cuando existen muchos viajes concentrados hacia un punto, el transporte público es necesario, fundamentalmente el de alta calidad, como el metro o los ferrocarriles suburbanos. Pero, obviamente el transporte público no compite en lo que a los viajes externos se refiere, o sea de suburbio a suburbio, porque es ineficiente. Por eso en los últimos 50 años, en las ciudades avanzadas el transporte público ha declinado en función del aumento del automóvil, que permite más flexibilidad e incluso economía, porque si dos personas van en un auto ya es más barato.

Discutió también Echenique la idea de subir la densidad urbana de Santiago desde 100 hab/ha bruta (en los hechos, del orden de 70 hab/ha bruta) hasta 150 hab/ha bruta ${ }^{41}$-incremento que ya

38 Al respecto puede verse CHILE, MOP-ME\&P-MECSA-INECON, 1995.

39 ROBINO, 2004

40 Ibídem.

41 MARCIAL Echenique: la densificación matará a Santiago. El Mercurio, 1996. había propuesto el Plan Intercomunal de Santiago desde 1960-, con el argumento que la metrópolis se expande a causa del mejor nivel de vida de los ciudadanos. Aumentar la densidad significaría, en su opinión, bajar la calidad de vida y contribuir a la congestión; la expansión de la ciudad hacia la periferia [matriz agrícola] no debería ser vista como algo "dramático" [la innovación tecnológica permitiría el volumen de producción de alimentos requeridos], y las zonas agrícolas se mantendrán por sí solas "si son rentables"; sólo habría que proteger ciertas áreas de belleza natural, "pero sin exagerar"42. Se observará que, al igual que en el área urbana, el paso de autopistas por los territorios regionales ampliando las comunicaciones, no está coordinado con un proyecto integral de desarrollo. Las autopistas sólo dan "visibilidad" a las tierras agrícolas de las áreas intermedias ${ }^{43}$.

Los estudios de Marcial Echenique \& P (1995) consideraron la situación de Santiago en el contexto de una Macro Zona Central de Chile, y señalaron finalmente:

Como conclusión general, el estudio demuestra que el sistema de vías expresas concesionadas da una alta rentabilidad social, con una importante distribución

42 Ibídem.

43 ÁLVAREZ, 2006.

ARTÍCULO: Marcha a pie urbana y regional y movilidad en los modelos de ciudad para Santiago de Chile / María Isabel Pavez Reyes 
a favor de los grupos sociales bajo y medio. Además, las concesiones son rentables privadamente para sus operadores. Este sistema de vías [autopistas de pago directo] puede perfeccionarse agregándole capacidad en los sectores sur y sur-oriente de la ciudad, ya que las concesiones propuestas no son suficientes para la demanda generada en esos sectores ${ }^{\prime 44}$.

En 2000, la Secretaría de Planificación de Transporte, SECTRA, en conjunto con otras entidades del Ministerio de Obras Públicas, Transporte y Telecomunicaciones, dio a conocer un nuevo Plan de Transporte Urbano para Santiago, PTUS 2000 2006, comprendiendo 12 programas, de los cuales el segundo (Modernización, ordenamiento e integración de servicios de transporte público, "Transantiago"), ha sido abordado, dando por resultado un conjunto de problemas aún no resueltos, por lo cual los habitantes de Santiago en vehículo privado no se motivan a pasar al transporte público ${ }^{45}$

\section{FACTIBILIDAD DE PASEABILIDAD PEATONAL DE SANTIAGO EN EL URBANISMO POR EL SECTOR PRIVADO, DESDE 1979}

En el modelo de ciudad dispersa emergente -donde el automóvil no es un lujo sino una necesidadel Anillo Orbital propuesto por el mismo Echenique no tiene relación con una planificación metro-

44 CHILE, MOP - ME\&P-MECSA-INECON, 1995

45 Se trata del 3er Plan de Transporte habido, un segundo Plan no fue implementado. politana y regional. Este anillo de circunvalación se asoció al despliegue de un modelo de baja densidad, que promueve los polígonos monofuncionales aislados (universidades, condominios residenciales, polígonos empresariales) -en una suerte de reedición a escala regional de las zonas de usos exclusivos del urbanismo del Movimiento Modernodonde se alejan las diversas actividades metropolitanas unas de otras, y son necesarias, por tanto, las autopistas (ahora de pago directo) -"a mayores velocidades, los autos contaminan menos"- y los malls, para poder existir. Aquí, no tiene cabida el peatón, pues las distancias hacen poco factibles el recorrido por este medio. En este tipo de ciudad se releva el buen vivir "en medio de la naturaleza", y se oculta el aumento de la jornada laboral generado por el incremento del tiempo de viaje de la casa al trabajo, también el peligro de accidentes en un contexto que no respeta las normas de circulación más elementales, y el sentido discriminatorio ${ }^{46}$ que implica la movilidad con vehículo privado para aquellas personas que por razones diversas (físicas, edad, renta, etc.) no pueden acceder al uso del vehículo, quedando a merced de la eventual buena voluntad y disponibilidad de tiempo de alguno de sus familiares o amigos con automóvil, para cualquier movimiento.

46 MIRALLES-GUASCH, Carme, 2002. 
Al interior de la ciudad, se lleva a cabo un proceso que construye autopistas y parques intercomunales y comunales por un extremo, y pasajes y plazas de vecindad por el otro, soslayando los espacios públicos viales y verdes de tamaño y dispersión media tan necesarios al desarrollo de la civilidad, a las personas de menor movilidad, a la regulación del microclima de los barrios. Además, se ha establecido una caducidad de corto plazo para los espacios públicos viales y verdes de cualquier escala proyectados y no construidos -se incluye el "Parque Metropolitano del río Mapocho", por ejemplo-, en función del Artículo 59 de la Ley General de Urbanismo y Construcciones ${ }^{47}$, todo lo

47 Artículo 59, Ley General de Urbanismo y Construcciones, DFL N 458 (Vivienda y Urbanismo) de fecha 18.12.75. D.0.13.04.76 y sus modificaciones y rectificaciones: Decláranse de utilidad pública, por los plazos que se indican en los incisos siguientes, los terrenos localizados en áreas urbanas y de extensión urbana consultados en los planes reguladores comunales e intercomunales destinados a vías expresas, troncales, colectoras, locales y de servicio y parques intercomunales y comunales, incluidos sus ensanches. Vencidos dichos plazos, caducará automáticamente la declarato ria de utilidad pública y todos sus efectos. [...] / Los plazos de caducidad para las declaratorias de utilidad pública de los terrenos ubicados en el área urbana, según su destino, serán de diez años para las vías expresas, y de cinco años para las vías troncales y colectoras y los parques intercomunales y comunales./ El plazo de caducidad de las declaratorias de utilidad pública de los terrenos ubicados en áreas de extensión urbana, cualquiera sea su destino, será de diez años, pudiendo prorrogarse por una vez por igual lapso./El plazo establecido para las declaratorias de utilidad pública de los terrenos ubicados en el área urbana destinados a vías troncales y colectoras y a parques intercomunales, podrá ser prorrogado, por una sola vez, por igual período. [...]. cual incidirá negativamente en la calidad de vida de los habitantes de Santiago.

En lo referido al área rural y su potencial recreacional, observamos que la última modificación propuesta al Plan Regulador Metropolitano de Santiago (Modificación PRMS 100) ${ }^{48}$, presentada en abril de 2010 -rechazada en su última etapa por el Gobierno Regional-, propone la actualización del límite urbano y la extensión del área urbanizable, definiendo una vialidad estructurante que conecta estos sectores con la ciudad consolidada y unos espacios verdes que incluyen "parques intercomunales" y "áreas verdes forestadas"

48 Plan Regulador Metropolitano de Santiago, MPRMS 100-Actualización Extensión Urbana y Reconversión Industrial. Provincias Santiago - Cordillera - Maipo.

49 HENRÍQUEZ 0., Patricia, 2010. 
Uno de los sectores para extensión urbana propuestos por esta modificación tiene como límite el río Mapocho en una longitud de $16 \mathrm{~km}$ aproximadamente. En ese borde, el Plan propone un sistema par de vías costaneras del río - de tipo troncal y colectoras- separadas por un "área verde de forestación”, que se desarrollan paralelas al cauce por el lado oriente del río. Este sistema vial a nivel metropolitano conecta la Ruta 68 camino a Valparaíso con la Ruta 78 o Autopista del Sol, camino al puerto de San Antonio, principales accesos a Santiago, extendiéndose $6,9 \mathrm{~km}$ de norte a sur. Una de las vías costaneras cruza el río y continúa su trazado por la ribera poniente, llegando hasta el límite de la provincia de Talagante, alcanzando un desarrollo total de $13,5 \mathrm{~km}^{50}$.

Para implantar las vías se requerirían obras de defensa de inundación a todo lo largo del cauce, alterando la dinámica y las funciones naturales del río. Por otra parte, las vías troncales y colectoras suponen velocidades hasta $80 \mathrm{~km}$, con flujos predominantes de automóviles, teniendo como consecuencia la obstaculización o directamente impidiendo el libre acceso al río.

\section{FIGURA 10. VIALIDAD TRONCAL Y SÍNTESIS PROPUESTA DE EXTENSIÓN URBANA. MEMORIA EXPLICATIVA MPRMS - 100}

EN la figura, el círculo señala las vías y zonas propuestas al borde del río Mapocho.

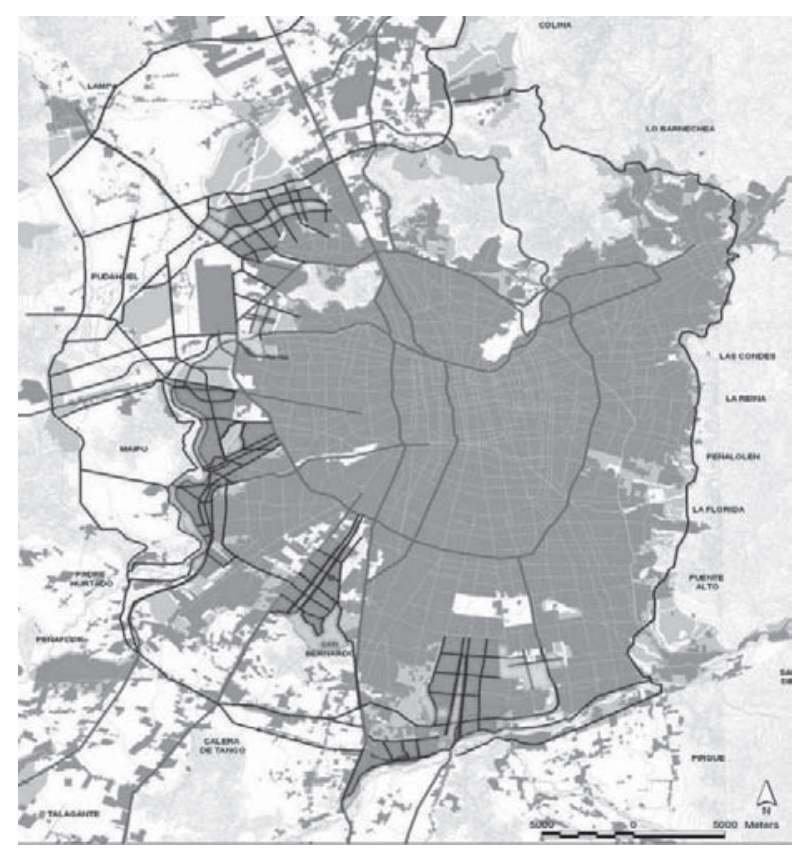

FUENTE: MINVU + Henríquez, 2010. 
Sin duda, el proyecto de costaneras no tiene un enfoque de sustentabilidad, repite el error de ocupar las áreas de ribera y lisa y llanamente las zonas inundables y, en los hechos, desestima la posibilidad de la marcha a pie y el paseo en bicicleta en las terrazas junto a las riberas del Mapocho51 - "Parque Metropolitano del río Mapocho", P.M.S. 1994-.

\section{Pensamiento siglo XXI sobre la marcha a pie -"paseabilidad" 52 peatonal, "caminabilidad" ("walkability")- y sustentabilidad}

La marcha a pie representa una mayor sustentabilidad ambiental frente a otros modos de desplazamiento, además de ventajas económicas, sociales y de salud, sin embargo, ella cada vez se va haciendo más difícil de practicar en la ciudad ${ }^{53}$. Y, en los suburbios, aparecerá reducida a los entornos de los malls comerciales -a los que es necesario llegar en vehículo-, estando asociada a formas de urbanismo pseudo-sustentables ${ }^{54}$.

51 Ibídem.

52 Neologismos utilizados por Pozueta, 2009, y otros autores, con 20 resultados en internet.

53 POZUETA, 2009.

54 Véase al respecto a GAJA I DÍAZ, 2009.
Estará operando aquí el grado de dispersión urbana, incidiendo en las pautas de movilidad: al separar las áreas urbanizadas, aumentan las distancias medias entre muchos orígenes y destinos, lo que resta posibilidades a la marcha a pie para realizarlos ${ }^{55}$.

El esquema de organización espacial en condominios, urbaniza paulatinamente el campo sin hacer ciudad; allí la feudalización del espacio genera megapolígonos no permeables al peatón, se trata de polígonos que tendrían que ser rodeados, en el mejor de los casos, para ir hacia otros destinos -como se rodea un cementerio o un regimiento-, aunque ello tampoco es posible allí. Los caminantes y ciclistas se verán volcados a las vías vehiculares colectoras o troncales, poniendo en riesgo sus vidas.

Por otro lado, a medida que las densidades urbanas disminuyen, las distancias median intraurbanas aumentan. La baja densidad estará asociada a un paisaje urbano menos estimulante y menos rico, será menos animado y menos seguro por la ausencia de la gente ${ }^{56}$.

Al disponerse los usos de suelo bajo la forma monofuncional, los desplazamientos urbanos más frecuentes entre distintos usos de suelo (vivienda a centros de empleo, a comercio, a escuelas, a servi-

55 POZUETA, et al., 2009.

56 Ibídem. 
cios, etc.), llevará irremediablemente a un aumento de las distancias medias de los viajes, reduciendo las posibilidades de marcha a pie para afrontarlas. La separación de los usos también reducirá la animación urbana, dejando amplias áreas vacías durante determinadas horas, haciéndolas poco atractivas, además de inseguras para los peatones ${ }^{57}$.

A comienzos del siglo XXI se promueve nuevamente avanzar hacia la mayor mezcla posible de usos de suelo compatibles con la residencia, y también en los tipos edificatorios con diseños favorables al concepto de ciudad "paseable" ${ }^{2}$. La relación entre edificación y espacio público se expresa a través de diversos rasgos: la mayor o menor separación del edificio respecto de la calle, la configuración y el grado de transparencia de la planta baja, la proporción de frentes de fachada a calle, la proporción entre anchura de calle y altura del edificio, el interés y riqueza de la edificación (composición, colores, materiales, texturas), su mayor o menor grado de apertura hacia la calle (disposición y carácter de los huecos), los usos en planta baja, el número y disposición de los accesos a la edificación, etc. ${ }^{59}$

En cuanto a la red peatonal y su acondicionamiento, señala Pozueta et al., que:

"Una red peatonal continua, sin lagunas o barreras, segura frente al tráfico automóvil, amplia y bien pa-

57 Ibídem

58 Ibídem.

59 Ibídem. vimentada, de pendientes moderadas, con áreas de estancia y mobiliario de apoyo, que discurre por calles o espacios atractivos y que tiene una estructura adecuada en relación a los flujos de la demanda de movilidad y una gran permeabilidad urbana [manzanas de tamaño adecuado], será sin duda más utilizada que una red sin estas cualidades"

El tamaño de la manzana y la anchura de la calle influyen significativamente en la accidentabilidad peatonal. Las propiedades de interrelación y conectividad (accesibilidad axial de la trama) indican que las calles más continuas y centrales reciben mayores flujos peatonales. En nuevas áreas de planeamiento urbano, la consideración de tramas de alta permeabilidad y conectividad o la concepción de redes de infraestructuras peatonales específicas, autónomas respecto de los trazados del viario rodado, constituyen los espacios más fructíferos para promover la marcha a pie urbana ${ }^{61}$.

Según los autores Pozueta et al. ${ }^{62}$, también es necesaria la valoración de la arquitectura en su funcionalidad a la marcha a pie segura y confortable. Sugieren considerar la accesibilidad a servicios y empleo (mixtura de usos compatibles en el edificio); la permeabilidad peatonal (atravieso por el interior de las manzanas y edificios); el confort climático (refugio y protección frente a la lluvia o las temperaturas extremas); la seguridad ciudadana y

60 Ibídem, pp. 62.

61 POZUETA et al., 2009

62 Ibídem. 
vial (grado de vigilancia natural de la calle, accesos a edificios); la animación (usos con actividades extendidas al máximo horario posible, cafés, cines de barrio); el interés visual del recorrido (vistas de interiores, fachadas), y el atractivo estancial.

No podemos desconocer que, en la arquitectura de las primeras décadas del siglo XX en el centro de Santiago de Chile, encontramos varios de los rasgos que definen una arquitectura más amigable con los peatones.

Pensamos que en los países en vías de desarrollo, considerando que habrá altos volúmenes de agua de escorrentía en cortos períodos de tiempo toda vez que no haya alcantarillado de aguas lluvias, se restringiría la marcha a pie en ciertas épocas del año por lo cual también podría agregarse la variable del confort a nivel de suelo (agua), pensando en la necesidad de aplicar técnicas alternativas a dicho alcantarillado, pues, especialmente en nuestra realidad, los costos para extender alcantarillados de aguas lluvias no se pueden solventar.
En lo referido al tratamiento de zonas no urbanas, ni urbanizables (naturales, paisajísticas, agrícolas, forestales), ellas deberían alojar sólo algunos equipamientos puntuales necesarios para cumplir las funciones por las que ha sido preservado. Aquí, mejorar las condiciones para la marcha a pie pasa por considerar caminos y sendas rurales existentes, que podrían formar parte de la red peatonal del municipio ${ }^{63}$. La posibilidad de realizar paseos a pie por las áreas rurales y naturales próximas a la ciudad no debe desatenderse ${ }^{64}$.

En el entorno de los lugares y ejes de atractivo de escala regional -como es el caso del corredor fluvial del Mapocho ${ }^{65}$ - debería eliminarse toda autopista en proximidad, siendo recomendable un esquema de aproximación vial en "peine"66.

\section{Conclusiones}

Ante la insoslayable ética de solidaridad con todos los habitantes del presente y del futuro que es necesario practicar, parece conveniente repensar el tipo de modelo de ciudad que conviene para

63 POZUETA et al., 2009, p.143. Puede verse también para la región de Santiago y río Mapocho ÁVALOS, et al. (2003).

64 La Fundación Sendero de Chile y la Asociación de Municipios Parque Cordillera firmaron recientemente un convenio en el que se fijaron como meta que de aquí a tres años exista al menos un sendero en cada una de las comunas que son parte del último organismo: Lo Barnechea, Las Condes, La Reina, Peñalolén, La Florida, San José de Maipo y Colina (El Mercurio, 22-10-2010).

65 Puede verse también CORTÉS, et al. (2003); y HERRERA et al. (2010).

66 POZUETA, J., 2009. Asesoría al proyecto FONDECYT 10901992002/2010. I. Responsable Dra. M.I. Pavez Reyes. 
Santiago, en el entendido que el sistema urbano es parte del sistema territorial global y que una política de desarrollo urbano debe ser parte de una política medio ambiental.

Se impone, en adelante, una aproximación ecológica de los asentamientos humanos que se interese en las maneras según las cuales el ciudadano entra en contacto con sus semejantes y con su entorno en sentido amplio: físico, social, económico, cultural. Estarán aquí presentes las "modalidades efectivas de la habitación" "67 las que no se limitan al departamento o a la casa, sino que significa también habitar una ciudad, una región, un país, una cultura, una naturaleza.

Cuando el planeta está amenazado por el calentamiento global y los cambios climáticos, y las ventajas de la marcha a pie, como parte de las formas sustentables de circular por la ciudad, son claras, debería trabajarse para llegar a formular un pacto cívico sobre la movilidad que incluya al peatón, con especial atención al de menor movilidad (adultos mayores -porcentaje en crecimiento en Chile-, minusválidos, niños).

Es necesario volver a planificar el sistema urbanoregional, lo que dice relación con los objetivos de eficiencia inversora, eficiencia técnica, justicia democrática y sostenibilidad. Una ciudad más compacta o mixta, y diversa, más una adecuada gestión ambiental supone un potencial de reducción

67 Al respecto puede verse AMAR, 1993. de la exagerada entropía generada por la hipermovilidad horizontal.

Las medidas para una movilidad urbana sostenible deben reducirelvolumendetráficogeneradoporeluso del vehículo particular, incentivando el paso de una parte significativa de los usuarios hacia el transporte público, y los desplazamientos a pie o en bicicleta.

Es necesario avanzar en un tipo de urbanismo y arquitectura que brinde acceso y facilidades a los peatones circulando por las aceras tradicionales, los paseos peatonales y las vías con templado de tráfico, los caminos rurales, los paseos de bordes de río y mares, lo que ayudará a que se incrementen los desplazamientos a pie por la ciudad y su región.

En el modelo para un Santiago más sustentable (modelo semi-compacto), aquellas vías y espacios públicos de tamaño y dispersión media -vías centralidades de barrio, parques de barrio para el juego de niños y adultos (2 a 6 hás.), que tanto promovió Karl Brunner, Muñoz Maluschka y sucesores, tan propicios para incentivar el desarrollo de la civilidad, la marcha a pie, el ciclismo-, no pueden seguir quedando desatendidos. Tanto más cuando para los adultos mayores, en incremento en Chile, los espacios públicos practicables también por ellos, y cercanos a su residencia, son su más relevante posibilidad de expansión cotidiana ${ }^{68}$.

68 No se trata aquí de los espacios de tamaño mínimo y dispersión máxima -al pie de la vivienda-que sólo sirven a los infantes. 


\section{Bibliografía}

ÁLVAREZ,Luis. Territoriose Infraestructura:Losimpactos de la generación de accesibilidad. Tesis de Magíster en Urbanismo. Prof. guía Alberto Gurovich W. Escuela de Posgrado, Facultad de Arquitectura y Urbanismo Universidad de Chile, 2006. 220 p.

AMAR, George. Pour une écologie urbaine des transports. En: Les Annales de la Recherche Urbaine: Mobilité, N59-60, Juin - Septembre, Paris, 1993, pp. 140-151. ISSN 0180-930X.

BARDET, Gaston. Demain c'est l'an 2000! Paris, Librairie Plon, Les Petits-Fils de Plon et Nourrit, Imprimeurs et Éditeurs, 1952.

CHILE, MOP, Dirección de Planeamiento - ME\&PMECSA-INECON. Análisis Programa estratégico de inversiones. Macro Zona Central. Síntesis ejecutiva, diciembre de 1995, 43 p. ilustradas.

CHOAY, Françoise. L'urbanisme, utopies et réalités, une anthologie, Editions du Seuil, 1965, pp. 358-366.

ECHENIQUE, Marcial. La densificación matará a Santiago. En: El Mercurio. Santiago de Chile, 17 de marzo de 1996. Cuerpo F.

GAJA I DÍAZ, Fernando. Urbanismo sostenible, urbanismo estacionario. Ideas para la transición. En: Revista Digital Universitaria, México, Volumen 10, Número 7, 10 de julio 2009, ISSN: 1067-6079 [consulta 05-11-2010]. http://www.revista.unam. mx/vol.10/num7/art41/art41.pdf.
HENRÍQUEZ O., Patricia. Directrices y conceptos de diseño de vialidad asociado al corredor fluvial del río Mapocho - Sección occidental. Tesina en Programa Doctoral. Director: Julio Pozueta E. Facultad de Arquitectura y Urbanismo Universidad de Chile - Universidad Politécnica de Madrid, 2010.88 p.

HOMO, León. La Roma Imperial y el Urbanismo en la Antigüedad. México, Unión Tipográfica Ed. Hispano Americana, 1956.

LABBÉ A., Ernesto y MÁRQUEZ R., Jaime. Vialidad urbana [entrevista al Arqto. Jaime Silva A., SubDirector de Vialidad Urbana Complementaria, Dirección General de Metro, Vialidad Urbana y Transporte Urbano]. En: Auca (27): 32-36, 1974.

MIRALLES-GUASCH, Carme. Ciudad y Transporte. El Binomio Imperfecto. España, Ariel Geografía, 2002. 250 p.

MUMFORD, Lewis. La carretera y la ciudad. Buenos Aires, Emecé, 1963.

PARROCHIA B., Juan (autor y co-a. cont.); PAVEZ R., M. Isabel (comp.). El Plan Tridimensional de Ordenamiento Territorial y la Región Metropolitana de Santiago 1960-2000, 2a edición, digital in extenso, Santiago de Chile, Ed. D. Urbanismo, F.A.U. U. de Chile, 1994, 130 p. ilus. color, rev. y amp., ISBN 956-19-0359-8. http://mazinger.sisib.uchile.cl/repositorio/lb/arquitectura_y_urbanismo/pavezmi01/ http://captura.uchile.cl/jspui/ handle/2250/5058 
PAVEZ R., M. Isabel. Vialidad y transporte en la metrópoli de Santiago 1950-1979: concepto y estrategia de ordenación del territorio en el marco de la Planificación Urbana y Regional por el Estado de Chile. Tesis Doctoral, Director Dr. Ing. J. Pozueta E., ETSA, U.P.M, Aprobada 13-11-2006, 418 p. (Cum Laude). (CH - R.P.I. N¹64.557. 2007). $1^{a}$ Ed. digital in extenso, 2007, Repositorio Académico U.P.M.: http://oa.upm.es/452/ $2^{\mathrm{a}}$ Ed. digital in extenso, 2008, Repositorio Académico U. de Chile: http://captura.uchile.cl/dspace/handle/2250/5098

POZUETA, Julio; LAMÍQUIZ Francisco y PORTO Mateus. La ciudad paseable, CEDEX, Madrid, España, 2009, 430 p. ISBN 978-84-7790-509-7.

QUIJADA, Rodrigo. Las políticas del Estado: sin brújula. En: LAFRANCO, Patricio, et al. Muévete por tu ciudad. Una propuesta ciudadana de transporte con equidad. Santiago de Chile, LOM, Ciudad Viva, 2003. Pp. 37-48.

RAPOSO M., Alfonso; VALENCIA P., Marco y RAPOSO 0., Gabriela. 2005. La interpretación de la obra arquitectónica y proyecciones de la política en el espacio habitacional urbano. Memorias e historia de las realizaciones habitacionales de la CORMU. Santiago 1966-1976. U. Central de Chile, F. Arquitectura, Urbanismo y Paisaje, C. E. A. U. P., 389 p.
REPÚBLICA DE CHILE. Comisión de planificación de inversiones en infraestructura de transporte, Secretaría Ejecutiva SECTRA, 1995. Plan de Desarrollo del Sistema de Transporte Urbano Gran Santiago 1995-2010. Santiago de Chile, 42 p.

ROBINO, Carolina. 2004. Marcial Echenique, Arquitecto y Urbanista. El Gran Impulsor. En: El Mercurio, Santiago de Chile, 6 de noviembre de 2004.

UNIVERSIDAD DE CHILE. Departamento de Extensión Cultural, Boletín Informativo No34, $2^{\mathrm{a}}$ y $3^{\mathrm{a}}$ Etapas del Seminario del Gran Santiago, Santiago, Chile, octubre de 1958. 